D.P. Dob BSC MB BS FRCA, C.N. Shannon MB BS FRCA, P.M. Bailey MB BS FRCA

\title{
Efficacy and safety of the laryngeal mask airway $v s$ Guedel airway following tracheal extubation
}

Purpose: To compare the safety and efficacy of the laryngeal mask airway (LMA) with the Guedel airway during the recovery period.

Methods: In a prospective randomised trial in the Post Anesthesia Care Unit (PACU), 52 patients (ASA $\mid$ and 2) were randomised to receive either a laryngeal mask airway ( $L M A: n=26)$ or a Guedel airway $(n=26)$ during the recovery period after middle ear surgery. Ease of airway maintenance was graded and the presence of coughing was noted. Peripheral arterial oxygen saturation $\left(\mathrm{SpO}_{2}\right)$ was measured continuously by pulse oximetry in the PACU. Readings were taken on arrival (time 0 ) and for five minutes afterwards.

Results: There was no difference in sex, age, weight or incidence of smoking between the two groups. In the LMA group 25 patients required no airway manipulation and only one patient required repositioning of the LMA. In the Guedel group severe difficulty maintaining the airway was experienced in two patients, moderate difficulty in five patients and mild difficulty in 12 patients. Seven patients required no ainway manipulation. The LMA group showed higher ease of airway maintenance scores, $(P=<0.000 \mathrm{I})$ and less coughing $(P=0.0496)$. At time 0 and at one minute the LMA group had higher median $\mathrm{SpO}_{2}(97 \%$ and $97 \%)$ than the Guedel group (95\% and 96\%), $\left(P=0.0002\right.$ and 0.0362). There was no further difference in $\mathrm{SpO}_{2}$.

Conclusions: The LMA provides easier airway maintenance, less coughing and initially higher median $\mathrm{SpO}_{2}$ when compared with the Guedel airway in the recovery period.

Objectif : Comparer la sécurité et l'efficacité du masque laryngé (ML) à celles de la canule oropharyngée de Guedel pendant la récupération de l'anesthésie.

Méthode : Lors d'un essai prospectif et randomisé à la salle de réveil (SR), 52 patients (ASA I et II) ont été répartis au hasard et on leur a installé un masque laryngé ( $M L: n=26)$ ou une canule oropharyngée de Guedel $(n=$ 26) pendant la récupération d'une chirurgie à l'oreille moyenne. On a coté la facilité à maintenir l'ouverture des voies aériennes et noté la présence de toux. La saturation du sang artériel périphérique en oxygène $\left(\mathrm{SpO}_{2}\right)$ a été mesurée de façon continue par oxymétrie pulsée à la SR. Les mesures ont été enregistrées à l'arrivée (temps 0 ) et cinq minutes plus tard.

Résultats : II n'y avait pas de différence de sexe, d'âge, de poids ou d'incidence de tabagisme entre les deux groupes. Dans le groupe ML, un seul patient a eu besoin d'un repositionnement du ML et non les 25 autres. Dans le groupe Guedel, il y a eu de sérieuses difficultés à maintenir l'ouverture des voies aériennes chez 2 patients, des difficultés modérées chez 5 patients et des difficultés mineures chez 12. II n'y a eu aucune manipulation chez 7 d'entre eux. Dans le groupe $M L$, on a noté des scores plus élevés quant à la facilité de maintenir la perméabilité des voies aériennes, $(P=<0,0001)$. et moins de toux $(P=0,0496)$. Au temps 0 et à une minute, les patients du groupe ML présentaient une $\mathrm{SpO}_{2}$ médiane plus élevée ( $97 \%$ et $97 \%$ ) que les patients du groupe Guedel $(95 \%$ et $96 \%),(P=0,0002$ et 0,0362$)$. II n'y a pas eu de différence dans la $\mathrm{SpO}_{2}$ par la suite.

Conclusion : Pendant le réveil, le ML, comparativement à la canule oropharyngée de Guedel, constitue un meilleur moyen de maintenir l'ouverture des voies aériennes, produit moins de toux et permet, au début, une $\mathrm{SpO}_{2}$ médiane plus élevée.

From the Royal National Throat Nose and Ear Hospital, Greys Inn Road, London WC1X 8DA United Kingdon. Address correspondence to: Dr P.M. Bailey, Phone: 181-878-1399; Fax: 181-876-3928.

Accepted for publication November 1,1998 
A IRWAY obstruction during the recovery period after anesthesia is a common cause of post-operative hypoxia and coughing. Traditionally, a Guedel airway is used to avoid airway obstruction by the tongue.

In an attempt to find a better solution to the problem we have developed a new strategy for airway management in the post anesthesia care unit (PACU), using the laryngeal mask airway (LMA)., ${ }^{1,2}$ Before extubation, a deflated LMA is placed behind the tracheal tube, the LMA cuff inflated, the tracheal tube removed, and muscle relaxation reversed allowing the patient to breathe spontaneously through the LMA. A soft bite block is then inserted beside the LMA. The LMA is usually well tolerated during recovery until protective reflexes have returned at which point, both may be removed.

We compared the safety characteristics of this new LMA technique with those of a traditional Guedel airway technique in a prospective randomised trial. Primary outcome measures were ease of airway management, incidence of coughing, and peripheral arterial oxygen saturation.

\section{Methods}

Approval for the study was given by the Hospital Ethics Committee who waived the need for written or verbal consent. Fifty-two patients (ASA class 1 and 2) undergoing middle ear surgery were randomly assigned to one of two groups. (Table I). Patients in both groups were anesthetised in a standard manner.

Anesthesia was induced with $1-2 \mathrm{mg} \cdot \mathrm{kg}^{-1}$ propofol and $2 \mu \mathrm{g} \cdot \mathrm{kg}^{-1}$ fentanyl. Muscle relaxation was achieved with $0.1 \mathrm{mg} \cdot \mathrm{kg}^{-1}$ vecuronium. The larynx sprayed with lidocaine $4 \%$ and the trachea intubated with an 8.0 or $9.0 \mathrm{~mm}$ RE preformed tracheal tube. The lungs were mechanically ventilated with nitrous oxide $66 \%$ and oxygen 33\%. Anesthesia was maintained with isoflurane. The patients were monitored with continuous ECG, non-invasive blood pressure, pulse oximetry, inspired and expired gas and vapour analysers and peripheral nerve stimulator. The $\mathrm{P}_{\mathrm{ET}} \mathrm{CO}_{2}$ was maintained at $3.5-5.0 \mathrm{kPa}$ and end-tidal isoflurane concentration at 0.6-1.2\%.

At the end of surgery airway management was carried out according to the initial randomisation.

\section{LMA Strategy Group}

The oropharynx was suctioned under direct vision. Before extubation a deflated LMA was placed behind the tracheal tube, whilst the lungs were ventilated with the maintenance mixture, and end-tidal isoflurane concentration was maintained at 0.6-1.2\%. The LMA cuff was inflated, the tracheal tube removed, and muscle relaxation reversed allowing the patient to breathe spontaneously through the LMA. A mixture of $2.5 \mathrm{mg}$ neostigmine and $0.5 \mathrm{mg}$ glycopyrollate was used to reverse the muscle relaxation and recovery of a train of four stimuli confirmed with the peripheral nerve stimulator. A roll of gauze swabs was then inserted beside the LMA to act as a bite block. When adequate spontaneous ventilation (respiratory rate $>10 \cdot \mathrm{min}^{-1}$ and $\mathrm{P}_{\mathrm{ET}} \mathrm{CO}_{2}<6$ $\mathrm{kPa}$ ) the patient was transferred to the PACU. The LMA was left in place during recovery until the patient was fully awake, at which point it was removed.

\section{Traditional Strategy Group}

The oropharynx was suctioned under direct vision. A Guedel airway was positioned beside the tracheal tube and muscle relaxation reversed as described above. When adequate spontaneous ventilation had returned the tracheal tube was removed. The airway was maintained with a jaw thrust throughout transfer.

Patients in both groups breathed the maintenance mixture throughout, and end-tidal isoflurane concentrations were maintained at $0.6-1.2 \%$ at extubation.

All patients were turned into a lateral recovery position after insertion of the relevant airway.

\section{Observations in the Operating Room}

Patients were observed for coughing and episodes of arterial oxygen desaturation in OR before transfer to the PACU. All patients were breathing spontaneously with a $\mathrm{SPO}_{2}>96 \%$ before transfer.

\section{Obserpations in PACU}

The $\mathrm{sPO}_{2}$ was measured continuously in the PACU. Readings were recorded on arrival (time 0 ) and at $1,2,3,4$, and $5 \mathrm{~min}$. Patients were observed for coughing which was noted as present or absent.

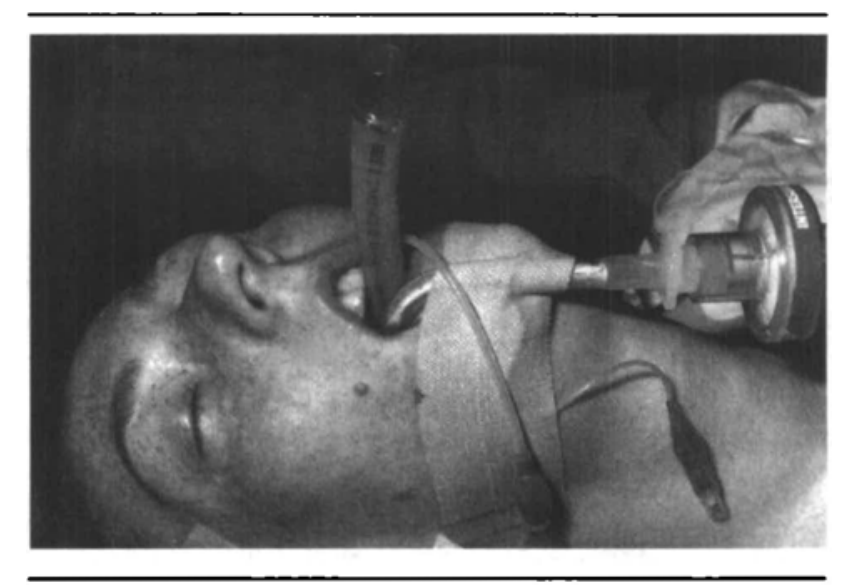

FIGURE The LMA positioned behind the tracheal tube. 
TABLE I Demographic Data

\begin{tabular}{lll}
\hline & LMA & Guedel \\
\hline Age (yr) & $43.3 \pm 13.1(21-71)$ & $41.6 \pm 12.6(18-60)$ \\
Sex & 13 male: 13 female & 13 male: 13 female \\
Weight $(\mathrm{kg})$ & $72.6 \pm 14.8(50-109)$ & $70.8 \pm 17.8(40-114)$ \\
Smokers & $8 / 26$ & $8 / 26$ \\
\hline
\end{tabular}

TABLE II Peripheral arterial oxygen saturation measurement $-\mathrm{sPO}_{2}$

\begin{tabular}{llll}
\hline Time & $\begin{array}{l}\text { Guedel Group } \\
\text { Median (range) }\end{array}$ & $\begin{array}{l}\text { LMA Group } \\
\text { Median (range) }\end{array}$ & $P$ \\
\hline 0 & $95(80-99)$ & $97(94-100)$ & 0.0002 \\
1 & $96(83-98)$ & $97(94-100)$ & 0.0362 \\
2 & $97(89-99)$ & $97(95-100)$ & NS \\
3 & $97(94-100)$ & $97(95-100)$ & NS \\
4 & $98(95-100)$ & $97(95-100)$ & NS \\
5 & $98(95-100)$ & $97(95-100)$ & NS \\
\hline
\end{tabular}

Ease of airway maintenance was graded:

$0=$ No manipulation required

$1=$ Minor adjustment required

$2=$ Jaw thrust required

$3=$ Ventilation with a mask and breathing system required

All observations were carried out by the recovery staff.

\section{Results}

\section{Demograpbic Data (Table I)}

There was no difference in sex, age, weight or incidence of smoking between the two groups.

\section{Airway management and coughing}

In the LMA group one patient required repositioning of the LMA. The remaining 25 in the group required no airway manipulation. In the Guedel group bag mask ventilation was necessary in two patients, jaw thrust in five patients and chin lift in 12 patients. Seven patients required no airway manipulation. $(P<$ 0.0001 , Mann- Whitney U test ). One patient in the LMA group coughed during recovery. Seven patients in the Guedel group coughed $(P<0.05$, Fisher's Exact Test ).

\section{Peripheral Arterial Oxygen Saturation (Table II)}

At time 0, patients in the LMA group had higher median arterial oxygen saturation than in the Guedel group. After one minute the median oxygen saturation for the LMA group was still higher than for the
Guedel group. There was no other difference in $\mathrm{sPO}_{2}$ between the two groups during the study.

\section{Discussion}

Airway obstruction during the early recovery period can result in hypoxia and coughing. This new LMA strategy helps to avoid these problems. ${ }^{1,2}$ A secure airway is provided throughout the transfer to the PACU and in the early recovery period. There may be some airway obstruction during the change from tracheal tube to LMA but this was not found in our study. The LMA provided a better airway in the recovery period in terms of ease of airway management, coughing and peripheral arterial oxygen saturation when compared with the Guedel airway. Also, there was a difference in the amount of work by recovery staff required to maintain a clear airway between the two groups. The reduction in coughing in the LMA group is an advantage after delicate middle ear surgery and may be useful for some types of nasal, plastic and neurosurgery.

Provided the patient is allowed to wake without interference obstruction to exhalation by the oxygen delivery system ${ }^{3}$ is avoided. The LMA strategy was safer and more effective in the PACU than the traditional Guedel airway technique.

\section{Acknowledgments}

We would like to thank the Recovery Staff at the Royal National Throat Nose and Ear Hospital, for their help with this study. We would also like to thank Dr Christine Dore phd of The Royal Postgraduate Medical School for advice on statistics.

\section{References}

1 Nair I, Bailey PM. Use of the laryngeal mask for airway maintenance following tracheal extubation (Letter). Anaesthesia 1995; 50: 174-5.

2 Glaisyer HR, Parry M, Lee J, Bailey PM. The laryngeal mask airway as an adjunct to extubation on the intensive care unit (Letter). Anaesthesia 1996; 51: 1187-8.

3 Newton NI. Supplementary oxygen-potential for disaster (Editorial). Anaesthesia 1991; 46: 905-6.

4 Woods $K$. When to remove the laryngeal mask airway (Letter). Anaesthesia 1993; 48: 175. 